Proceedings of the $51^{\text {st }}$ Hawaii International Conference on System Sciences | 2018

\title{
Collaboration Engineering: Reflections on 15 Years of Research \& Practice
}

\author{
Gert-Jan de Vreede \\ University of South Florida \\ gdevreede@usf.edu
}

\author{
Robert Briggs \\ San Diego State University \\ rbriggs@mail.sdsu.edu
}

\begin{abstract}
Collaboration Engineering (CE) is an approach for the design and deployment of repeatable collaborative work practices that can be executed by practitioners without the ongoing support of external collaboration professionals. Research on CE started in the early 2000 s with studies on ways to transfer professional collaboration expertise to novices using a pattern language called thinkLets. Subsequent research focused the development of theories to explain key phenomena, the development of a structured design methodology, training methods, technology support, design theories, and various field and experimental studies focusing on specific aspects of the CE approach. This paper provides an overview of the different phases and key contributions of $C E$ research and looks ahead at the research opportunities that are emerging as our society, organizations, technologies, and the nature of collaboration evolve.
\end{abstract}

\section{Introduction}

Organizational teams form to create value that would be challenging to achieve by individual effort. In recent decades, teamwork became an important structure for organizational work. In the 1970s, researchers began to develop and study collaboration technologies, and by the early 1990s, reported major benefits. Users only realized that value, though, with the help of scarce and expensive collaboration experts. Collaboration Engineering (CE) was founded with a goal to to extend the benefits of facilitated group interactions to teams with no collaboration experts, and thus to increase their performance on high-value recurring collaborative tasks. CE's core foci are a) on the design of effective and repeatable technology-supported collaborative work processes for high-value tasks, and b) on how to transfer the designs to practitioners with little or no training on either the tools or the techniques [10,53].

The origins of CE trace back to a 2001 HICSS publication that proposed the contours of a collaboration pattern language called 'thinkLets' to teach novice team leaders repeatable and effective collaboration techniques [11]. Over the course of the next 15 years, an active research community formed that developed, applied, and studied CE principles in laboratory and field settings to build the CE body of knowledge. Early work focused on conceptual and theoretical work, followed by action research and design science research. Many studies build on the findings, limitations, and future research directions from earlier work.

Hundreds of CE related studies were published, which were cited by thousands more. Dozens of minitracks and sessions have been organized at conferences such as HICSS, GDN, and AMCIS. A special issue was published in the Journal of the AIS in 2009 [53]. PhD Dissertations in CE and CE-related phenomena have been successfully completed in the US, Europe, Africa, and Australia. To the best of our knowledge, CE-research funding totals in the double digit millions.

Since the inception of $\mathrm{CE}$, the nature of organizational teams and collaboration has evolved. New collaborative structures emerged, such as community crowdsourcing and open innovation. New technologies and platforms have emerged such as social media, mobile apps, and artificial agents that support individual and team-based problem solving. New streams of $\mathrm{CE}$ research have begun to investigate their potential.

At this juncture, it would be valuable to take stock of the contributions of $\mathrm{CE}$ research and to look ahead at at the new areas where $\mathrm{CE}$ researchers can continue to create value for teams and organizations.

The purpose of this paper is thus twofold. First, we provide a condensed overview of the history of $\mathrm{CE}$ research and its key contributions. Second, we outline future research directions to stimulate continued scientific inquiry into ways to make individuals that jointly create value more productive.

The next four sections provide an overview of the history of $\mathrm{CE}$ research in four phases. Section 6 summarizes key insights from past research. We conclude with a discussion of new directions for $\mathrm{CE}$ research.

\section{Phase I: Transferring facilitation techniques}

Early CE research was grounded in an interesting phenomenon discovered by GSS researchers: many organizations abandon GSS installations after one-tothree years, even in with compelling evidence in hand of triple-digit returns on investment $[1,10]$. Research showed the root cause to be complexity; most teams did not how to design effective processes, and did know how to configure the many capabilities of a GSS 
to support their processes. They resorted to professional facilitators, with whose help they could realize discontinuous improvements in speed, cost, and quality. However, besides being expensive to hire and train, facilitators were difficult to retain over time; their skills gave them rapid upward mobility. Researchers proposed a way to codify a facilitator's expertise in such a way that it would be easy for teams to learn by themselves. This codification resulted in the thinkLets pattern language [10,37,54]. A thinkLet is a named, scripted procedure that reliably creates predictable variations in the patterns of collaboration by which a group moves through its activities. They are facilitation best practices. ThinkLet documentation distills to its essence the concepts a team leader needs to know to reproduce those effects in groups working toward a joint goal. ThinkLets codify techniques that collaboration professionals use time and again across many situations. For example, professional facilitators use specific techniques when a team needs to brainstorm on multiple topics simultaneously, or when the team needs to organize ideas into a set of categories. ThinkLets represent a pattern language as proposed by Alexander [54]: a collection of good design practices and solutions for recurring design problems.

In its original conceptualization, each thinkLet had a name, and it specified just three elements [10,11]:

1. The collaboration technology the team should use

2. The way the technology should be configured

3. A script for the team leader to follow, which includes the prompts to team, the behaviors and events to monitor for, and any decisions that must be made based on the team leader's observations.

This conception though, made the techniques technology-dependent. Further research produced a more detailed and technology-independent conceptualization of thinkLets that situated a technique in a larger context of relationships among objects (Figure 1). The key elements were [26,28]:

1. Name, an easy-to-remember mnemonic.

2. Capabilities, the affordances a collaboration tool would have to provide to support the procedure. By defining capabilities instead of specifying the configuration of a specific tool, thinkLets could be used on different platforms. E.g. brainstorming needs a shared page capability., which could be realized with paper, a wall of stickies, or a computer screen.

3. Actions: What participants do with the capability. Researchers found that six canonical actions could specifiy a thinkLet: add, modify, associate, judge, aggregate, and delete.

4. Rules, defining what action each role should take using what capabilities under what constraints.
5. Roles, which describe the specific actions and rules that different actors in the team setting are responsible for. For example, a Devil's Advocate must perform different actions than a regular participant in an ideation task.

6. Parameters, which specified the information that must be provided to the team to effectively execute the thinkLet. For example, a multiple topic brainstorm must provide the brainstorm question and the different topics.

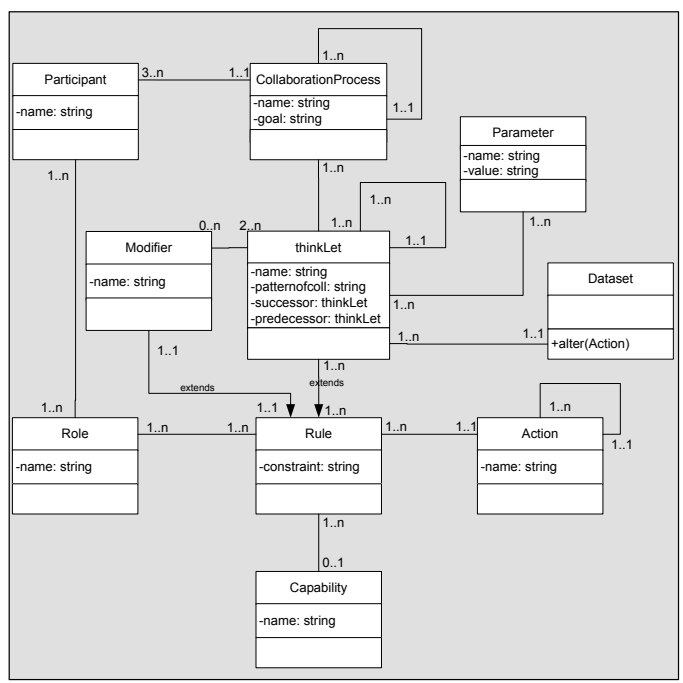

Figure 1. ThinkLet conceptualization [26].

Other notable CE research efforts in this phase focused on comparing the effects and effectiveness of different thinkLets $[46,47]$ and on extracting recurring thinkLet sequences from historical workshop data [25].

\section{Phase II: The Collaboration Engineering Approach}

ThinkLets originated to transfer a distilled set of proven techniques to novices. The second phase of $\mathrm{CE}$ research focused on transferring fully engineered processes. Its main thrusts were a) creating a structured approach to $\mathrm{CE}, \mathrm{b})$ discerning how best to transfer engineered work processes to practitioners, and c) developing theoretical foundations to explain key collaboration phenomena.

Researchers used the Five Ways framework to guide research on a structured CE approach [60]:

- Ways of Thinking: defines how an approach conceives the object of design. It defines key terms, models key phenomena, and details an approach's design philosophy.

- Ways of Working: defines the design steps, their interrelationships, deliverables, and KPIs.

- Way of Modeling: defines ways to represent aspects of designed objects, e.g. structured 
visualizations and descriptions of designed objects.

- Way to Control:, defines the project management aspects of an approach.

- Way of Supporting: prescribes tools and technologies to support design activities.

Most of the the second phase research focused on the Ways of Thinking, Working, and Modeling.

\subsection{CE Way of Thinking}

Researchers defined $\mathrm{CE}$ as an approach to designing collaborative work practices for high-value recurring tasks, and to deploying those designs for practitioners to execute for themselves without ongoing support from professional facilitators [7]. The key object of design, collaboration, was defined as joint effort towards a common goal [7]. A collaboration process is a sequence of steps performed by a group to achieve a goal [24]. Researchers further defined six patterns of collaboration, which are observable regularities that teams go through during a period time [30]:

- Generate: To move from having fewer concepts to having more concepts, e.g. brainstorming.

- Reduce: To move from having many concepts to having a focus on fewer concepts deemed worthy of further attention, e.g. through filtering concepts or abstracting a more general concept from multiple instances.

- Clarify: Moving from less to more shared meaning of the concepts under consideration.

- Organize: To move from less to more understanding of the relationships among the concepts, e.g. by sorting a set of ideas into categories.

- Evaluate: To move from less to more understanding of the value of concepts toward a goal, e.g. estimating the required effort for user stories.

- Build Consensus: To move from having more to having less disagreement among stakeholders on proposed courses of action, e.g. stakeholders identifying a set of solutions that produce value for each individual as well as achieve the team goal.

Researchers further identified two new roles in the context of a CE effort [33]. In traditional collaboration settings, there are participants (e.g. team members) and a facilitator. The participants execute the process that the facilitator has designed. This process design is typically specifically created for the challenge that the team has to address. In $\mathrm{CE}$, the first new role is the Collaboration Engineer, a collaboration expert that can design a collaboration process is such a way that (s)he can instruct team leaders to execute it by themselves. Thus, a collaboration engineer creates 'leave-behind' collaboration process designs. The second new role is the Practitioner. A practitioner is a domain expert, who is in charge of executing the collaboration process. It is someone who has experience in the subject matter that the team is working on, but with limited facilitation expertise. A practitioner typically has to guide to execution of the same type of process frequently. Examples of practitioners are risk managers who guide risk assessments, SCRUM Masters who guide user story generation exercises, or military leaders who execute After Action Reviews.

A final critical part of the CE approach's way of thinking concerns the notion of 'design guided by theory'. CE researchers have developed a number of causal theories that explain phenomena of interest that are critical to $\mathrm{CE}$, such as satisfaction (Yield Shift Theory [9]), transition of work practice (Value Frequency Model [3,8,35]), creativity (Cognitive Network Model of Creativity [46]), and consensus (Instrumentality Theory [6]). These theories inform designs to collaboration engineers when they determine the sequence of activities in a collaboration process or the selection of specific thinkLets.

\subsection{CE Way of Working}

The CE approach distinguishes between two phases (figure 2): the design phase, where the collaboration engineer creates a thinkLets-based collaboration process prescription for a repeatable process, and the deployment phase, where the process prescription is implemented in the organization following the training of a number of practitioners. During the deployment phase, the process prescription can be further updated based on the practitioners' experiences.

To understand the design practices of experienced facilitators and collaboration engineers, researchers collected surveys and conducted in-depth interviews $[24,29,52]$. This informed the initial design approach, which was further fine-tuned in a series of four field studies [24]. The resulting way of working for the CE design phase consists of five main steps:

1. Task diagnosis, consisting of an analysis of the task, the stakeholders, available resources, and practitioners.

2. Task decomposition, consisting of pattern decomposition and process result decomposition.

3. ThinkLet choice, focusing on mapping thinkLets to the steps in the process.

4. Agenda building, including the creation of the Facilitation Process Model and Agenda Notation Model.

5. Validation, which takes place by performing one of more of the following: pilot testing, walkthrough, simulation, and expert evaluation.

Figure 2 illustrates the way of working in more detail. 
Further research on the CE design phase focused on making the CE investment decision [61], on an approach to identify and select among $\mathrm{CE}$ opportunities [5], and testing the efficacy of the design approach in practice [23,27].

The structure of a $\mathrm{CE}$ training program was informed by Cognitive Load Theory (CLT) [39]. CLT distinguishes between three types of cognitive load that impact individuals' learning. Intrinsic cognitive load is the interaction of an individual's capabilities and task complexity. Extraneous cognitive load relates to how information is presented. High levels of intrinsic and extraneous cognitive load may cause cognitive overload if they leave too little working memory capacity available. Germane cognitive load concerns designs and procedures that aid the processing, construction, and automation of schemas. A schema is a knowledge framework that represents a class of things, events, and situations. CE researchers crafted the specifications of the documentation from the $\mathrm{CE}$ design phase to minimize intrinsic and extrinsic cognitive load, while stimulating germane load. They also developed a training program structure consisting of lectures, simulation, coaching, observation and selfstudy [32]. The effectiveness of the training program was demonstrated in a longitudinal field study [31].

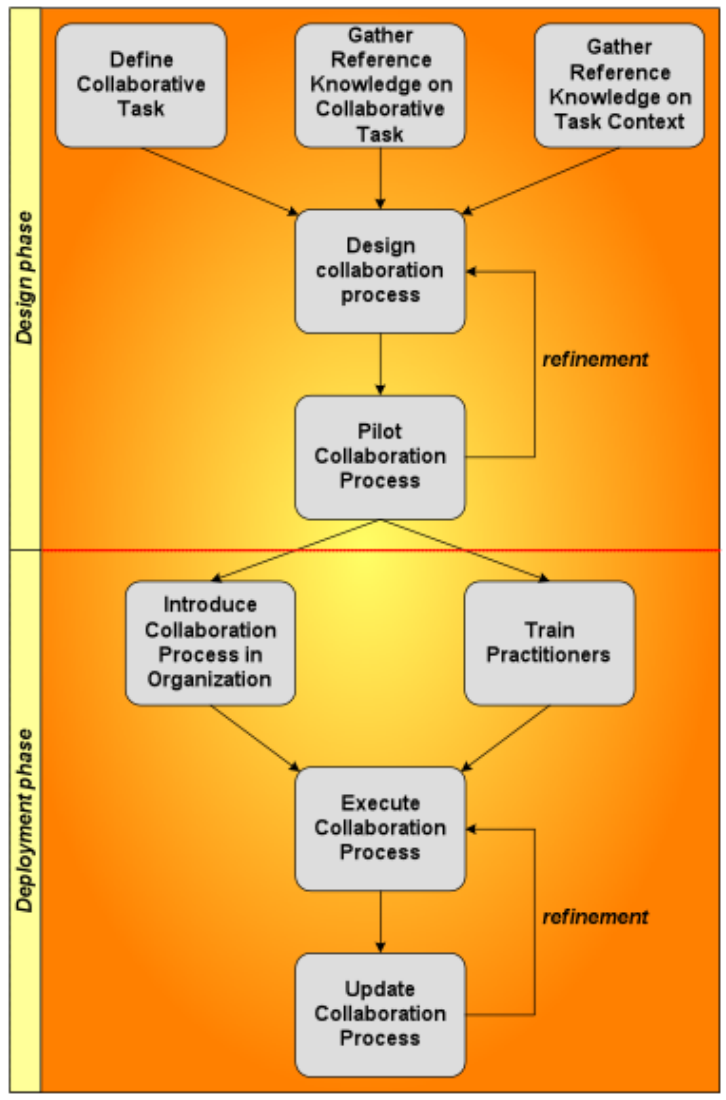

Figure 2. The CE approach's Way of Working

\subsection{CE Way of Modeling}

Research concerning the CE way of modeling yielded two specific modeling techniques to capture relevant elements of a collaboration process design. The first model, a Facilitation Process Model (FPM), is a CEspecific flowchart, depicting the activities of a work practice along with the conditional logic for their order of execution. Each activity appears with a name, a brief description, the pattern of collaboration it aims to produce, the thinkLet to be used, the nominal start time and length of the activity, and activity deliverables. The logical flow between the steps is depicted by arrows for flow direction and circles for decision points. An FPM is a high-level map of the process design that is often a training aid for practitioners. Examples of FPMs can be found in [10,56].

The second model, an Agenda Notation Model (ANM), captures more details about how to execute the process flow represented by an FPM. It provides a compact, structured, textual representation of the full script for executing the process. A collaboration engineer uses it to capture details of the physical design for the process. A practitioner uses it as a cheatsheet to guide the process at execution time. An ANM specifies the name and duration of each activity, the thinkLet to be used, the input and output parameters of the thinkLet, the tool(s) and configuration(s) used for the activity, and any task specific guidance for the group to initiate the activity. An example of an ANM can be found in [53].

\section{Phase III: Design Tools \& Technologies}

The third phase in CE research concerned on Ways of Supporting collaboration engineers. Early efforts focused on providing collaboration engineers with automated advice regarding the selection of thinkLets based on the characteristics of the task, team, and practitioner $[34,36,45]$. More recent efforts took up the challenge of making it possible for practitioners to execute engineered work practices without training, to realize the underlying philosophy of the CE [10]. While earlier phases of $\mathrm{CE}$ research focused on codifying professional collaboration expertise in a form that practitioners could easily learn, and developing a systematic approach to design and deployment, the third phase investigated the feasibility of packaging the collaboration expertise with the technology in a form that practitioners could use with no training. The aim was to present a practitioner with just the tools they needed for each activity, with just the right configuration, displaying just the right data, and with precise guidance they needed to execute the task. . 
This 'Facilitator-in-the-box' concept was prototyped in a CE design environment consisting of three elements [12,15]: The Computer Assisted Collaboration Engineering platform (CACE), a Process Support System (PSS) runtime platform, and a library of Process Support Applications (PSA). The CACE allows a collaboration engineer to create specific PSAs. The PSS runtime platform allows practitioners to instantiate a PSA for their specific process needs and execute it. For example, a collaboration engineer uses the CACE to capture the design of a user story generation process in as a thinkLets-based activity sequence and user interaction screens. A SCRUM Master (practitioner) can select the User Story PSA from a library, instantiate it for a specific workshop (e.g. by defining the start date and time, number of team members, and specific thinkLet parameters), and then execute it with the team. Experiments with this rapid-development environment showed (1) that it reduces the development time for online collaboration systems by three orders of magnitude, (2) that it allows non-programmers to design and develop PSAs, and (3) that it packages enough collaboration expertise in the PSA that non-experts could execute a well-designed process without training [12].

The other significant contribution in the third phase concerned CE reference models: the Seven Layer Model of Collaboration (SLMC) (Figure $3)[13,44]$. It considers collaboration processes at seven levels of abstraction. It became and organizing structure for the hundreds of constructs, metrics, theories, design concerns, and best practices in the $\mathrm{CE}$ domain. Design choices at a higher layer constrained design choices at the lower layers, so the model was a useful structure for CE design methodologies. The separation of design concerns aims to reduce cognitive load for collaboration engineers and improve completeness of their collaboration process designs.

\begin{tabular}{|l|l|}
\hline \multirow{2}{*}{ Why } & 1. Goals \\
\cline { 2 - 2 } & 2. Products \\
\hline \multirow{2}{*}{$\begin{array}{l}\text { Howat } \\
\text { (Logical Design) }\end{array}$} & 3. Activities \\
\cline { 2 - 2 } & 5. Patterns of Collaboration \\
\cline { 2 - 2 } & 5. Techniques (ThinkLets) \\
\hline \multirow{2}{*}{ (Physical Design) } & 6. Tools \\
\cline { 2 - 2 } & 7. Scripts \\
\hline
\end{tabular}

Figure 3. Seven Layer Model of Collaboration [13].

\section{Phase IV: Deepening}

$\mathrm{CE}$ research is now in its fourth phase. This phase is characterized by a range of efforts that focus on deepening our understanding of various CE aspects and phenomena, the application of $\mathrm{CE}$ in practice, the transfer of $\mathrm{CE}$ knowledge and expertise, and the certification of collaboration engineers.

\subsection{Convergence}

Much of the prior research on collaboration patterns focused on idea generation (brainstorming). Hundreds of studies have been published detailing the effects of different techniques, instructions, and tool support on the number, creativity, and quality of ideas that teams produce $[20,40]$. A recent research stream now focuses convergence, a superset of the Reduce and Clarify patterns. It concerns moving a group from having many ideas to a focus on fewer ideas deemed worthy of more attention [48]. Research shows convergence to be the most challenging pattern for facilitators to lead [18], and so, by deduction, for practitioners.

Initially, CE researchers focused on defining performance measures for convergence thinkLets [17] and on coding approaches to enable a detailed assessment of the utility of a convergence outcome [2]. Seeber and colleagues performed a series of in-depth explorations of the efficacy of several convergence thinkLets for work quality and participant satisfaction [48]. Their findings suggest that convergence quality may improve by the use of explicit convergence procedures, and by engaging teams in structured conversations to clarify and reduce ideas. They further found teams using convergence interventions reported higher post-convergence satisfaction did teams that did self-managed teams [48]. A separate study based on Control Theory [21] found that teams that used engineered convergence processes had deeper interactions and a greater degree of idea development than did self-managed teams [50]. They also found a positive correlation between leaders' and members' agreement on their depth of interaction and the extent of development of the ideas in the set of convergence results.

\subsection{Comprehensive $\mathbf{C E}$ applications}

While CE has been applied in a significant number of organizations, few large-scale field studies have yet been reported. A recent effort under the authority of the Advanced Practices Council of the Society for Information Management provided an opportunity to conduct and report on two in-depth case studies [56]. Both studies involved the design of a mission-critical collaboration process and training a group of practitioners to lead the repeated execution of the process in the host organizations. The first case, at Verisk Analytics, concerned an innovation ideation process to support interdisciplinary teams identifying potential product innovations and develop initial business plans for the most promising innovations. The 
second case at Howard Hughes Medical Institute (HHMI) concerned a SCRUM backlog creation process where business representatives worked with IT professionals to identify, organize, and prioritize the user stories in the initial backlog for new IT projects. Both projects were deemed a success by the host organizations. The participants and practitioners found the engineered collaboration processes to be more productive and effective than past approaches. The cases provided recommendations for the organizational application of the $\mathrm{CE}$ approach, including the identification of a critical collaboration process that can serve as a CE pilot case, accommodating the goals of all critical stakeholders, and developing basic collaboration competencies among practitioners and team members.

\subsection{CE Education}

The growing the body of CE knowledge has enabled researchers to develop courses that focused on teaching university students facilitation techniques, foundations of collaboration, and $\mathrm{CE}$ design techniques. For example, graduate courses on thinkLets-based facilitation have been successfully organized at universities in the Netherlands, the United States, Austria, South Africa, and China. An undergraduate and graduate version of a course on Principles of Collaboration has been developed using the SLMC as an organizing framework [57]. It is currently offered at at least three US universities.

Graduate special topics classes on $\mathrm{CE}$ have been offered in Germany, the US, and China. Also, a model syllabus for a graduate course on $\mathrm{CE}$ was developed and published under the auspices of the Association for Information Systems (AIS). This course focuses on theories and models of group collaboration, computersupported collaborative work, methods and tools for designing group collaboration, and the application of $\mathrm{CE}$ techniques to solve a real-world problem [14].

Finally, both executive training programs for thinkLets-based workshop design, and formal collaboration engineering training are now being conducted by numerous organizations in the US Europe, and Africa.

\subsection{CE Professionalization}

A number of $\mathrm{CE}$ researchers are currently working on professionalizing the $\mathrm{CE}$ area. Their objectives include:

- Developing a formalized, detailed description of the CE approach and its underlying philosophy [43].

- Formalizing quality indicators for CE performance for each CE step and deliverable [42].

- Articulating a set of professional standards for practicing $\mathrm{CE}$.
- Formalizing a professional training and certification program for collaboration engineers that create thinkLets-based processes.

- Developing an online resource of CE materials for researchers, consultants, and organizational managers and team leaders.

\section{Key Insights}

The past 15 years have shown a variety of CE research to support collaborative value creation in organizations. The usefulness of the $\mathrm{CE}$ approach has been demonstrated by the number of organizations that have adopted collaborative work practices that were designed and deployed using the approach. The scientific quality of the CE approach has been assessed through the structured peer review process to which most of the CE publications have been subjected. From the experiences in the field and lab, a number of key insights can be extracted.

First, while it is clear that progress has been made to provide advanced support for improving the performance of teams working together towards a goal, collaboration remains a complex, intricate phenomenon. Per the logic of the SLMC, there are many design considerations that collaboration engineers need to consider. The interplay between these considerations is too complex to study comprehensively in controled or realistic environments. Furthermore, it can be argued that the SLMC does not capture all design considerations. Thus, while progress has been made, significant work remains.

Second, the CE field experiences demonstrate that the CE approach reduces organizations' need for collaboration professionals. For example, at ING Group over 600 risk professionals were trained during a period of 10 years in a collaborative risk \& control self-assessment (RCSA) process. These practitioners have conducted thousands of assessment workshops across the world. As experiences showed early on that the RCSA workshops yielded predictable results, both in terms of quality and quantity of risk related information, ING designated the RCSA process as its company standard. Before adopting the CE approach to develop a repeatable RCSA process to be executed by their own risk professionals, the organization was actually considering to hire external consultants to conduct assessment workshops. The cost savings as a result of the $\mathrm{CE}$ approach are thus significant.

Third, CE design goes beyond a specification of 'what' needs to be done in a collaboration process. It specifies the 'how' as well. The CE approach guides designers to document a collaboration process in sufficient detail that a practitioner can follow a detailed script to execute it. 
Forth, the core focus of the CE approach is the collaborative work practice. Unlike the majority of GSS research in the 80s and 90s, it is not technologycentric. It is not stakeholder-centric either; it does not focus on a specific team or team leader. A focus on the work practice ensures that designs are more likely to last over time. Technologies change continuously. Thus, by focusing designs on capabilities that need to be afforded, a collaboration process design can become technology-independent. Internal facilitators, team leaders, and other organizational actors may leave the organization or move to new positions. A design solution that is specific to these people will be difficult to transfer to their successors. Thus, taking a work practice centric perspective increases the likelihood that an organization can sustain access to the process design over time. In short, people move on, technologies change, yet practices stay as long as there is a need for the practice. This makes it more likely that $\mathrm{CE}$ designs last.

Fifth, experiences show that thinkLets-based collaborative work practices can be easily and successfully transferred to groups of practitioners. The RCSA process at ING Group could be trained in a twoday intensive session. The processes at Verisk Analytics and HHMI could be successfully transferred in a 5-hour training session after the trainees had observed the execution of the process once in person. This compares favorably to the months of on-the-job training that is typically required to teach someone to become an effective internal facilitator [1].

Sixth, CE focuses on the capabilities that collaboration tools need to afford to support the application of a thinkLet. This makes thinkLets a technology-independent pattern language. It also enables CE process designs to be executionable on both electronic and paper-based platforms. For example, the early pilots at ING Group were executed on a GSS, whereas the worldwide rollout was mostly paper-based using flipcharts, notepads, PostIt notes, and voting stickers. The Verisk Analytics process was paper-based as well, whereas the HHMI process used a GSS.

Seventh, research on CE is an example of researchers going 'the Last Research Mile': successfully transitioning a scientific solution to a real world problem in to the workplace [38]. CE researchers have navigated all elements of the last research mile. They have performed proof-of-concept research to demonstrate the feasibility of solutions, e.g. the thinkLets pattern language to transfer facilitation skills and process design or the prototype of $\mathrm{CE}$ design studio consisting of the CACE, PSS, and PSAs. They have performed a variety of field studies that demonstrate proof-of-value; their $\mathrm{CE}$ designs have been successfully used for issues such as software code inspections [55], collaborative standards writing [22], and incident response planning [16]. Finally, proof-of-use has been demonstrated through the adoption and routine use of CE process designs by a significant number of organizations (e.g. ING Group, Verisk Analytics, and HHMI). By taking its research through the last research mile it can be argued that the $\mathrm{CE}$ research community is making a significant impact on both science and society.

Finally, the decade and a half of $\mathrm{CE}$ research demonstrates the value of programmatic research. By focusing on a research topic in a concerted way, it is possible to build a research program with a motivated group of collaborating researchers. A research program facilitates designing future research studies, introducing young researchers into the area, and developing a reputation over time. This gives a twofold benefit. As the productivity of the research program continues to grow, the academic credibility increases as well. Further, programmatic research allows striving for both breadth and depth in the investigation of a research phenomenon. This makes it more likely that researchers develop solutions that have both solid scientific foundations and practical applicability. In other words, a dedicated research program caters to both rigor and relevance.

\section{Collaboration Engineering - Quo Vadis?}

Current CE research efforts focus on interesting challenges. Yet, there are additional developments and opportunities for $\mathrm{CE}$ researchers to pursue. We outline a few.

\subsection{The expanding conception of collaboration}

The conception of collaboration has expanded over the past decade. Organizations still use established teams working toward specific deliverables during a planned periods. Newer collaboration modes, though, have emerged. These are characterized by dynamic teams, dynamic deliverables, and endless engagement. For example, crowdsourcing approaches allow organizations to assemble large numbers of people to contribute to specific organizational challenges to the extent and for the duration they wish to be involved [41]. The nature of products has changed to the point where innovation and development teams continuously update and deploy new versions, creating a cycle of constant co-creation. This new reality represents a vertile ground for CE research. Researchers can build on the existing knowledge base to develop new theories, techniques, and design approaches to answer questions such as: How to design for sustained engagement [58]? What are facilitation and governance best practices for crowdsourcing projects? What repeatable techniques can support convergence and creativity in crowds [49]? What should be included in a library of design patterns for crowdsourcing processes? 


\subsection{The expanding conception of teams}

We commonly think of a team as a collection of people working together towards a goal. Recent technological advances make us broaden this conceptualization. With the introduction of digital agents like Siri, Alexa, and Watson, there is a growing realization that in the near future it will be common for some team members to be robots or artificial agents [59]. Early studies have demonstrated the effectiveness of so-called Special Purpose Embodied Conversational Intelligence with Environmental Sensors (SPECIES) Agents to support individual and team decision-making [19]. Current prototypes such as the social robot Jibo give a glimpse into a future where artificial agents will become fully functional members of teams and families [4]. Key CE questions include: Can artificial agents perform the role of a practitioner? How can we design processes that establish and sustain trust between human and artificial team members? Which collaboration monitoring and advising tasks can automated agents perform [51]?

\subsection{Design Theory}

CE is a design approach with the thinkLets pattern language and the SLMC at its core. CE provides collaborative solutions for recurring challenges. However, a complete design theory for $\mathrm{CE}$ has not yet been published. To what principles should collaboration engineers adhere when they sequence activities and map thinkLets? How should we translate the logic of theories (e.g. for creativity, satisfaction, consensus, idea quality, and group productivity) into design guidelines that make it more likely that a designed process improves outcomes of interest? What recurring sequences of thinkLets provide superior performance on certain dimensions than do others? Future research could focus on developing and refining a CE design theory as a collection of knowledge that future CEs can use to develop their own solutions.

\subsection{The forgotten domain: Education}

CE has touched many domains and sectors to test out concepts and solutions, including but not limited to: the financial sector, manufacturing, product development \& innovation, military decision making, medical standards development, software engineering, project management, and organizational town halls. Yet, surprisingly, few have yet deployed CE to enhance education. This is surprising given that the majority of $\mathrm{CE}$ researchers are also academic educators. The classroom, be it on location or at a distance, is essentially a collaborative theater where students and educators work together to create and share knowledge. Research has shown that collaborative learning approaches are often superior to individual approaches.
This environment thus provides a fertile application area for CE: How can we develop a library of thinkLetsbased in-class and online student team activities? How can we design collaborative learning processes that motivate and engage learners to actively participate? How can we teach students collaborative process leadership to better prepare them for the collaborative workforce? And, how can we overcome educators' resistance to change to adopt more collaborative learning practices in their classroom environment?

\section{Conclusions}

For over 15 years, $\mathrm{CE}$ has been an active and productive area of research that has attracted scientists from different backgrounds and disciplines. Together, the $\mathrm{CE}$ research community has produced a notable body of knowledge in this area. This paper has given an overview of the history of CE research and its key contributions. It has also outlined a number of future directions to stimulate continued scientific inquiry.

It is impossible to include and discuss every CE study in the scope of this paper. Likewise, there are additional areas and opportunities for further research in this field as well. Yet it is our hope that the CE research community will address the challenges, known and unknown, that lay ahead. The need for high performance collaboration has not diminished in recent years. On the contrary, the increasing complexity of organizational innovation, operations, and management has made high performance collaboration a 'sine qua non' for organizational survival. New realities concerning the nature of teams, technologies such as social media and AI, and modern collaborative work forms make this an exciting era for collaboration science and practice.

\section{Acknowledgments}

Numerous colleagues and students have made significant $\mathrm{CE}$ research contributions. The findings and contributions detailed in this paper are inspired by their work. It would be impossible to list all of them here. Rather, we acknowledge the various institutions that have actively worked together to develop and grow the CE field, in alphabetical order: AVT Business School, Bingham Young University, City University Hong Kong, Delft University of Technology, DePaul University, Institut Telecom, Johannes Kepler University Linz, Kassel University, Manchester Business School (UK), University of Innsbruck, University of International Business \& Economics, University of Nebraska at Omaha, University of Pretoria, University of Zurich, Washington State University, and Western Illinois University. 


\section{References}

[1] Agres, A., Vreede, G. J. de, \& Briggs, R. O. (2005). A Tale of Two Cities - Case Studies on GSS Transition. Group Decision \& Negotiation, 14(4), 267-284.

[2] Badura, V., Read, A., Briggs, R., \& Vreede, G.J. de (2011). Coding for Unique Ideas and Ambiguity: A method for measuring the effect of convergence on the artifact of an ideation activity. Intern. Journal of Social and Organizational Dynamics in Information Technology, 1(3), 1-17.

[3] Boughzala, I., \& Briggs, R. O. (2012). A value frequency model of knowledge sharing: an exploratory study on knowledge sharability in cross-organizational collaboration. Electronic Markets, 22(1), 9-19.

[4] Breazeal, C. (2017, March). Social Robots: From Research to Commercialization. In Proceedings of the 2017 ACM/IEEE International Conference on HumanRobot Interaction.

[5] Briggs, R. O., \& Murphy, J. D. (2011). Discovering and evaluating collaboration engineering opportunities: An interview protocol based on the value frequency model. Group Decision \& Negotiation, 20(3), 315-346.

[6] Briggs, R. O., Kolfschoten, G. L., \& Vreede, G. J. de (2005). Toward a theoretical model of consensus building. AMCIS 2005 Proceedings, 12.

[7] Briggs, R. O., Kolfschoten, G. L., Vreede, G. J. de, \& Dean, D. L. (2006). Defining Key Concepts for Collaboration Engineering, $12^{\text {th }}$ AMCIS, Acapulco, Mexico, 121-128.

[8] Briggs, R. O., Murphy, J. D., Carlisle, T. F., \& Davis, A. J. (2009). Predicting change: a study of the value frequency model for change of practice. 42nd HICSS.

[9] Briggs, R. O., Reinig, B., \& Vreede, G. J. de (2008). The Yield Shift Theory of Satisfaction and Its Application to the IS/IT Domain. Journal of the Association for Information Systems, 9(5), 267-293.

[10] Briggs, R.O., Vreede, G.J. de, \& Nunamaker, J.F., Jr. (2003). Collaboration Engineering with thinkLets to pursue sustained success with Group Support Systems. Journal of Management Information Systems, 19(4), 31-63.

[11] Briggs, R. O., Vreede, G. J. de, Nunamaker, J. F. Jr., \& Tobey, D. (2001). ThinkLets: Achieving Predictable, Repeatable Patterns of Group Interaction with Group Support Systems (GSS). 34th HICSS.

[12] Briggs, R.O., Kolfschoten, G.L, Vreede, G.J. de, Lukosch, S., \& Albrecht, C. (2013). Facilitator-in-the-box: Process Support Applications and Computer Assisted Collaboration Engineering to Help Practitioners Realize the Potential of Collaboration Technology, Journal of Management Information Systems, 29, 4, 159 - 194.

[13] Briggs, R., Kolfschoten, G., Vreede, G.J. de, Dean, D., \& Lukosch, S. (2009), A Seven Layer Model of Collaboration: Good Technology is Not Enough, $30^{\text {th }}$ ICIS.

[14] Briggs, R.O., Leimeister, J.M., Söllner, M. (2015), Collaboration Engineering, AIS Reference Syllabi, Ed.: J. vom Brocke, Eduglopedia.org, 2015.

[15] Buttler, T., Janeiro, J., Lukosch, S., \& Briggs, R. O. (2011, October). Beyond GSS: fitting collaboration technology to a given work practice. In International Conference on Collaboration and Technology (pp. 126141). Springer, Berlin, Heidelberg.
[16] Davis, A. J., Kamal, M., Schoonover, T. V., Nabukenya, J., Pietron, L. R., \& Vreede, G. J. de (2008). Incident Response Planning Using Collaboration Engineering Process Development and Validation. Journal of Information System Security, 4(3), 24-45.

[17] Davis, A., Vreede, G.J. de, \& Briggs, R. O. (2007, August). Designing thinkLets for convergence. Proceedings of the 13th Annual Americas Conference on Information Systems (AMCIS-13), Keystone, Colorado.

[18] den Hengst, M., \& Adkins, M. (2007). Which Collaboration Patterns Are Most Challenging: A Global Survey of Facilitators. 40th HICSS.

[19] Derrick, D., Read, A., Callens, A., Nguyen, C., Vreede, G.J. de (January, 2013). Automated Group Facilitation for System Requirements Generation, $46^{\text {th }}$ HICSS.

[20] Fjermestad, J., and Hiltz, S. R. 1998. "An Assessment of Group Support Systems Experimental Research: Methodology and Results," Journal of Management Information Systems (15:3), pp. 7-149.

[21] Henderson, J. C., and Lee, S. 1992. "Managing I/S Design Teams: A Control Theories Perspective," Management Science (38:6), pp. 757-777.

[22] Kocsis, D., Vreede, G.J. de, Briggs, R.O. (2015). Designing and Executing Effective Meetings with Codified Best Facilitation Practices. In S. Rogelberg, J. Allen, and N. Lehmann-Willenbrock (Eds.), The Cambridge Handbook of Work Meetings, New York, NJ: Cambridge University Press.

[23] Kolfschoten, G. L. (2007). Theoretical foundations for collaboration engineering (Doctoral dissertation, TU Delft, Delft University of Technology).

[24] Kolfschoten, G. L., \& Vreede, G. J. de (2009). A Design Approach for Collaboration Processes: A Multi-Method Design Science Study in Collaboration Engineering. Journal of Management Information Systems, 26, 1, 225-256.

[25] Kolfschoten, G. L., Appelman, J. H., Briggs, R. O., \& Vreede, G. J. de (2004). Recurring Patterns of Facilitation Interventions in GSS Sessions. 37th HICSS.

[26] Kolfschoten, G. L., Briggs, R. O., Vreede, G. J., de, Jacobs, P. H. M., \& Appelman, J. H. (2006). A Conceptual Foundation of the ThinkLet Concept for Collaboration Engineering. International Journal of Human Computer Science, 64(7), 611-621.

[27] Kolfschoten, G., Duivenvoorde, G., Briggs, R.O., Vreede, G.J. de (2009). Practitioners vs. Facilitators a comparison of participant perceptions on success. 42nd HICSS.

[28] Kolfschoten, G. L., Grünbacher, P., \& Briggs, R. O. (2011). Modifiers for quality assurance in group facilitation. Group Decision and Negotiation, 20(5), 685-705.

[29] Kolfschoten, G. L., Hengst, M. den, \& Vreede, G. J. de (2007). Issues in the Design of Facilitated Collaboration Processes. Group Decision \& Negotiation, 16, 347-361.

[30] Kolfschoten, G. L., Lowry, P. B., Dean, D. L., Vreede, G. J. de, \& Briggs, R. O. (2014). Patterns in Collaboration. In J. F. Nunamaker Jr, N. C. Romano Jr, \& R. O. Briggs (Eds.) Collaboration Systems: Concept, Value, and Use. Armonk, NY: M.E. Sharpe, Inc. 
[31] Kolfschoten, G. L., Vreede, G. J. de, \& Pietron, L. R. (2011). A training approach for the transition of repeatable collaboration processes to practitioners. Group Decision \& Negotiation, 20, 3, 347-371.

[32] Kolfschoten, G.L., Hulst, S. van der, Hengst, M. den, Vreede, G.J. de (2012). Transferring Collaboration Process Designs to Practitioners: Requirements from a Cognitive Load Perspective. International Journal of eCollaboration, 8, 3, 36-57.

[33] Kolfschoten, G.L., Niederman, F., Briggs, R.O., Vreede, G.J. de (2012), Facilitation Roles and Responsibilities for Sustained Collaboration Support in Organizations, Journal of Management Information Systems, 28, 2, 129-162.

[34] Kolfschoten, G.L., Veen, W. (2005) Tool Support for GSS Session Design. $38^{\text {th }}$ HICSS.

[35] Murphy, J. D., Wolcott, P., \& Briggs, R. O. (2010). A Reconceptualization of the Value Frequency Model. Proceedings of the $11^{\text {th }}$ Group Decision \& Negotiation 2010, Delft, The Netherlands, pp. 1-15

[36] Murphy, J.D., Petter, S., Cheng, K., Briggs, R.O. (2008). Hitting the Collaboration Target: ComputerGuided thinkLet Selection. DESRIST, Atlanta, GA.

[37] Niederman, F., Briggs, R. O., Vreede, G. J. de, \& Kolfschoten, G. L. (2008). Extending the Contextual and Organizational Elements of Adaptive Structuration Theory in GSS Research. Journal of the Association for Information Systems, 9(10).

[38] Nunamaker Jr, J. F., Briggs, R. O., Derrick, D. C., \& Schwabe, G. (2015). The last research mile: Achieving both rigor and relevance in information systems research. Journal of Management Information Systems, 32(3), 10-47.

[39] Paas, F., Renkl, A., Sweller, J., (2004). “Cognitive load theory: Instructional implications of the interaction between information structures and cognitive architecture," Instructional science (32:2), pp.1-8.

[40] Paulus, P., Kohn, N., Arditti, L., Korde, R. (2013). Understanding the Group Size Effect in Electronic Brainstorming. Small Group Research (44:3) 332-352.

[41] Pedersen, J., Kocsis, D., Tripathi, A., Tarrell, A., Weerakoon, A., Tahmasbi, N., Xiong, J., Deng, W., Oh, O., Vreede, G.J. de (January, 2013). Foundations of Crowdsourcing: A Review of IS Research. $46^{\text {th }}$ HICSS.

[42] Randrup, N., \& Briggs, R. (2015, January). Evaluating the Performance of Collaboration Engineers. 48th HICSS.

[43] Randrup, N., Druckenmiller, D., \& Briggs, R. O. (2016, January). Philosophy of Collaboration. 49th HICSS.

[44] Read, A., Hullsiek, B., \& Briggs, R. O. (2012, January). The Seven Layer Model of Collaboration: An Exploratory Study of Process Identification and Improvement. 45th HICSS.

[45] Rosoy, G. (2009). Designing a computer assisted collaboration tool: The journey from design to implementation. University of Nebraska at Omaha.

[46] Santanen, E., Briggs, R. O., \& Vreede, G. J. de (2004). Causal Relationships in Creative Problem Solving: Comparing Facilitation Interventions for Ideation. Journal of Management Information Systems, 20(4), 169-200.

[47] Santanen, E. L., \& de Vreede, G. J. (2004). Creative approaches to measuring creativity: comparing the effectiveness of four divergence thinkLets. 37th HICSS.
[48] Seeber, I., Maier, R., Weber, B., Vreede, G.J. de, Vreede, T. de, \& Alothaim, A. (January, 2015). Brainstorming is just the beginning: Effects of convergence techniques on satisfaction, perceived usefulness of moderation, and shared understanding in teams. $48^{\text {th }}$ HICSS.

[49] Seeber, I., Merz, A., Vreede, G.J. de, Maier, R., Weber, B. (January, 2017). Convergence on Self-Generated vs. Crowdsourced Ideas in Crisis Response: Comparing Social Exchange Processes and Satisfaction with Process. 50 $0^{\text {th }}$ HICSS.

[50] Seeber, I., Waizenegger, L., Demetz, L., Merz, A., Vreede, G.J. de, Maier, R., Weber, B. (December, 2016). IT-Supported Formal Control: How Perceptual (in)Congruence Affects the Convergence of CrowdSourced Ideas. International Conference on Information Systems, Dublin, Ireland.

[51] Vivacqua, A. S., Marques, L. C., Ferreira, M. S., \& de Souza, J. M. (2011). Computational indicators to assist meeting facilitation. Group Decision and Negotiation, 20(5), 667-684.

[52] Vreede, G. J. de, Boonstra, J., \& Niederman, F. (2002). What Is Effective GSS Facilitation? A Qualitative Inquiry Into Participants' Perceptions. 35th HICSS.

[53] Vreede, G. J. de, Briggs, R., \& Massey, A. (2009). Collaboration Engineering: Foundations and Opportunities. Journal of the AIS, 10, 3, 121-137.

[54] Vreede, G. J. de, Kolfschoten, G. L., \& Briggs, R. O. (2006). ThinkLets: A Collaboration Engineering Pattern Language. International Journal of Computer Applications in Technology, 25(2/3), 140-154.

[55] Vreede, G. J. de, Koneri, P. G., Dean, D. L., Fruhling, A. L., \& Wolcott, P. (2006). A Collaborative Software Code Inspection: The Design and Evaluation of a Repeatable Collaborative Process in the Field. International Journal of Cooperative Information Systems, 15(2), 205-228.

[56] Vreede, G.J. de (2014). Achieving Repeatable Team Performance through Collaboration Engineering: Experiences in Two Case Studies. Management Information Systems Quarterly Executive, 13, 2, 115-129.

[57] Vreede, G.J. de, \& Briggs, R.O. (2011). Facilitation of Technology Supported Collaboration. Omaha: The Center for Collaboration Science.

[58] Vreede, T. de, Nguyen, C., Vreede, G.J. de, Boughzala, I., Oh, O., Reiter-Palmon, R. (October, 2013). A Theoretical Model of User Engagement in Crowdsourcing, CRIWG 2013, Wellington, New Zealand, October 30 - November 1, 2013.

[59] You, S., Robert, L.P. (in press). Emotional Attachment, Performance, and Viability in Teams Collaborating with Embodied Physical Action (EPA) Robots, Journal of the Association for Information Systems.

[60] Seligmann, P., Wijers, G., Sol, H.G. (1989, November). Analyzing the structure of IS methodologies. Proceedings of the First Dutch Conference on Information Systems. Amersfoort, The Netherlands.

[61] Dean, D. L., Deokar, A., \& Ter Bush, R. (2006, January). Making the collaboration engineering investment decision. 39th HICSS. 